\title{
ISSN: $2668-6384$
}

https://conferenceproceedings.international

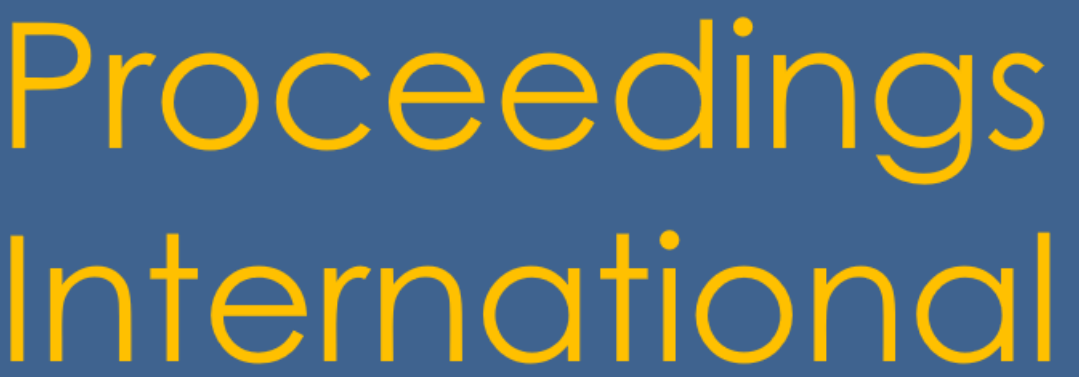

Volume 1, Issue 1, Pages 0019-0020

2019

Proceedings, Abstract

\section{Composite hydrogels with application in wound healing}

A.C. Bîrcă 1, 2, *, A.M. Grumezescu 1,2 , F. Iordache ${ }^{4}$, A.M. Holban ${ }^{3}$, A.O. Stoica 1, 2 , I.A. Neacșu 1,2, B.S. Vasile 1,2, V.A. Surdu ${ }^{1,2}$, R. Trușcă ${ }^{1,2}$

1 Faculty of Applied Chemistry and Materials Science, Politehnica University of Bucharest, Bucharest, 060042, Romania

2 National Centre for Micro and Nanomaterials, Politehnica University of Bucharest, Bucharest, 060042, Romania

3 Microbiology-Immunology Department, Faculty of Biology, University of Bucharest, Bucharest, 050095, Romania

4 Faculty of Veterinary Medicine, University of Agronomic Science and Veterinary Medicine, Bucharest, 011464, Romania

* Correspondence: ada_birca@yahoo.com; Scopus ID: 57203357672

More and more worrying cases of patients with wound infections caused by resistance to antibiotic drug treatment in many bacterial strains have led to advanced research to solve this common problem, which may even cause death. Mixing a hydrogel with some antimicrobial agents leads to a composite dressing that includes the characteristics required for successful healing, reassuring the properties of each material used, and thus ensuring the action of all at one place, compared to their action [1].

The present work is centralized on wound healing using a polyvinyl alcohol and alginate hydrogel that includes silver nanoparticles and antimicrobial mandarin oil. Thus, the focus is based on the release of antimicrobial agents at the site of the wound and on maintaining a wet environment for faster and more healing to absorb a significant amount of exudate and, last but not least, to present biocompatibility [2].

The paper presents the methods of analysis applied on the obtained hydrogels for wound treatment, using physical-chemical analyzes such as FT-IR, XRD, SEM, TEM and biological test based on the evaluation of the antibacterial activity of the composite hydrogels and on their biocompatibility assessment, which showed suitable results of dressing in wound dressing applications.

Keywords: hydrogels, wound healing, silver nanoparticles, TEM, SEM, XRD.

\section{Funding}

Not applicable.

\section{Acknowledgments}

Not applicable.

\section{Conflicts of Interest}

The authors declare no conflict of interest. 
A.C. Bîrcă, A.M. Grumezescu, F. lordache, A.M. Holban, A.O. Stoica, I.A. Neacșu, B.S. Vasile, V.A. Surdu, R. Trușcă
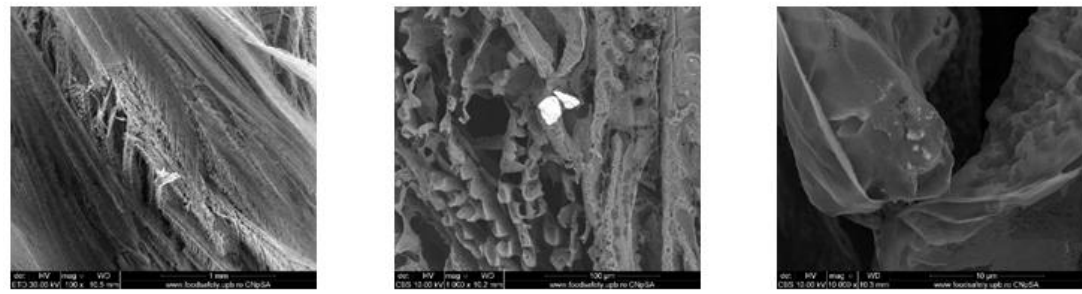

Figure 1. SEM images for PVA_Alg_Ag hydrogel.
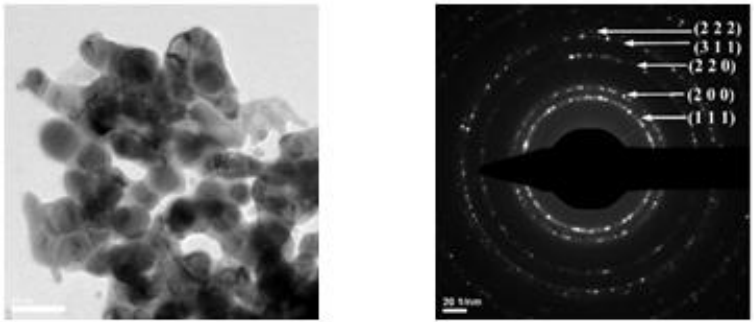

Figure 2. TEM and SAED images for Silver Nanoparticles with mandarin oil.
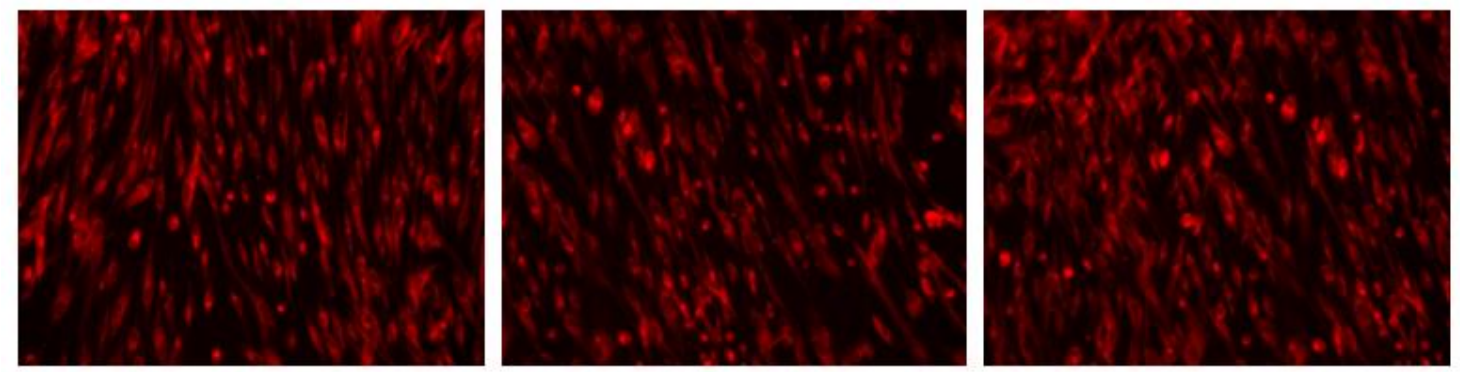

Figure 3. Fluorescent microscopy of AFSC cells treated with the obtained hydrogel.

\section{References}

1. Gunasekaran, T.; Nigusse, T.; Dhanaraju, M.D. Silver Nanoparticles as Real Topical Bullets for Wound Healing. Journal of the American College of Clinical Wound Specialists 2011, 3, 82-96, based hydrogel films for wound healing applications. International Journal of Biological Macromolecules 2013, 52, 221-230, https://doi.org/10.1016/j.jcws.2012.05.001.

https://doi.org/10.1016/j.ijbiomac.2012.09.031

2. Pereira, R.; Carvalho, A.; Vaz, D.C.; Gil, M.H.; Mendes, A.; Bartolo, P. Development of novel alginate

(C) 2019 by the authors. This article is an open access article distributed under the terms and conditions of the Creative Commons Attribution (CC BY) license (http://creativecommons.org/licenses/by/4.0/). 